\title{
Estrategias mercadológicas e innovación en las artesanías, una tradición transformadora
}

\author{
Handcrafts marketing \\ strategies and innovation, a \\ transforming tradition
}

\author{
Perla Shiomara del Carpio Ovando (México) \\ shiomarartesania@gmail.com \\ Doctora y maestra en Psicología Social \\ Universidad de Guanajuato Campus Celaya-Salvatierra
}

\section{Resumen}

Este artículo tiene como objetivo principal conocer y analizar las ramas artesanales y el origen de los artesanos que han participado en las vertientes de apoyo del Fondo Nacional para el Fomento de las Artesanías (Fonart). Como estrategia metodológica se acudió a la investigación cualitativa documental y a la realización de algunos ejercicios estadísticos. Las fuentes de información fueron registros de Fonart, correspondientes al año

\begin{abstract}
Summary
This article aims to identify and analyze craft branches and artisans who have participated in the support aspects of the National Fund for Handicrafts Promotion (Fonart) origin. As methodological strategy, we used qualitative documentary research, and carried out some statistical exercises. The sources of information were 2009 and first half of 2010 Fonart archives, regarding craftsmen who participated in four areas: support in raw materials, training courses, microcredits
\end{abstract}

PARA CITAR ESTE artículo / to CITE thIS ARTICle

Del Carpio Ovando, P.S. (2016). Estrategias mercadológicas e innovadoras en las artesanías, una tradición transformadora, Bogotá: Editorial Politécnico Grancolombiano, Poliantea, 12(23), pág 77-1 10 
2009 y al primer semestre de 2010, y conciernen a artífices que participaban en cuatro vertientes: apoyo en materia prima, cursos de capacitación, acceso y canalización a microcréditos, y oportunidad y apoyo para participar en expo-ventas nacionales. Actualmente, esta instancia ha sumado dos vertientes: el área de salud y los concursos de arte popular. En los resultados se señala que en México se elaboran productos provenientes de una gran variedad de ramas artesanales cuyos productores tienen orígenes diversos. Las ramas artesanales con mayor cantidad de artesanos beneficiados (por lo menos para el periodo que aquí se analiza), fueron: textiles, alfarería y fibras vegetales. En estas ramas artesanales las mujeres son quienes llevan la batuta en cuanto a cantidad de artífices registrados se refiere lesto sigue vigente). Enfrentan múltiples problemas: precariedad económica, comercialización, intermediación, bajos precios, competencia industrial, impacto del oficio en la salud, necesidad de mayor organización, comunicación y acuerdo entre los integrantes del gremio. Sobresale la necesidad de generar estrategias múltiples: información sobre financiamiento, capacitación y comercialización; protección de los derechos de autor, vinculación del sistema educativo nacional para fomentar la valoración de las artesanías y generar políticas públicas para la innovación y mejora de esta tradición transformadora, y de sus artífices.

Palabras clave: artesanías, ramas artesanales, innovación. access and channeling, and opportunity and support for participate in national expo-sales. Currently, this instance has added two aspects: health area and popular art competitions. Results show that in Mexico, crafts are produced from a wide variety of artisan branches whose manufacturers have different origins. The artisan branches with greatest number of benefited craftsmen (at least in the analyzed period) were: textiles, pottery and vegetable fibers. In these artisanal branches women lead in terms of registered craftsmen quantity (this is still valid). They face multiple problems: economic precariousness, commercialization, intermediation, low prices, industrial competition, craft impact in health, need for greater organization, communication and agreement among the guild members. The need to generate multiple strategies stands out: financing information, training and marketing; copyright protection, linkage of the national education system to promote handicrafts appreciation and generate public policies for innovation and improvement of this transformative tradition, and its craftsmen.

Key words: crafts, artisan branches, innovation. 


\section{Introducción}

La producción artesanal en México se realiza en un país en el que su origen, elaboración, materiales, diseño, comercialización, canales de distribución, consumo y valoración es diverso y cuya población tiene múltiples diferencias de acceso a recursos, bienes, servicios, origen étnico y a aspectos que hacen evidentes no solo diferencia sino también desigualdad. Válgase insistir en que las causas debemos quizá buscarlas en nuestra historia, en esos vericuetos que dan cuenta de la diversidad cultural que ha hecho de México un país pluricultural. Es ese el panorama que invita a autoras como Novelo (1997), a calificar la realidad cultural mexicana como plural, multifacética, clasista, estratificada, compleja, contradictoria, heterodoxa y riquísima que solo puede entenderse de manera cabal a la luz de la realidad social y su muy particular historia que se ha formado con elementos tan variados como las sociedades indígenas, la sociedad mestiza, la industrialización importada, la rápida urbanización y la vecindad con el país colindante (Estados Unidos).

Este panorama influye o salpica, de una u otra manera, la producción artesanal, esta que crea objetos decorativos y utilitarios donde se condensan aspectos económicos, sociales y culturales que reflejan la cosmovisión de los pueblos originarios. Autores como Martínez-Peñaloza (1982) ven a las artesanías como formas con las que una comunidad conserva y transmite su peculiaridad física y espiritual. Constituyen elemento importante en la indumentaria, la utilería doméstica, la simbología ceremonial, se asocian a las festividades comunitarias, representan un universo de formas, 
colores, texturas y materiales en que se inscribe la vida individual y colectiva de quienes lo realizan. En conjunto, para este autor, es arte popular porque expresa la voluntad de ser, de un modo propio y peculiar del grupo indígena.

Diferentes autoras (Novelo, 1997; Zapata y Suárez, 2007), indican que México es un país multicultural en el que cada núcleo étnico produce diferentes formas de expresión. No nacen solamente por "inspiración", advierten Zapata y Suárez (2007), sino que están profundamente arraigadas al ambiente que rodea a los artesanos para aprovechar los recursos naturales de la zona en la que viven y responden a las necesidades religiosas o culturales de la comunidad de sus hacedores, por ello adquieren su carácter tradicional. Por esto es importante considerar que en el estudio de la producción de artesanías deben también considerarse las condiciones estructurales en que se inserta y desarrolla la actividad (Valverde, 2007). Hay que partir, entonces, de una caracterización de la actividad artesanal como constitutiva de relaciones sociales (Novelo, 1976), que remite a la economía y la subsistencia, a la vez que a la identidad y al patrimonio cultural de un grupo (Morey, 2007).

En el abordaje de estas elaboraciones debe así considerarse la convergencia de líneas teóricometodológicas superpuestas donde confluyen, como indica Cardini (2007): el enfoque cultural y lo económico; los procesos identitarios y de memoria; lo tradicional y patrimonial, y también el ámbito psicosocial donde se gesta y desarrollan estas producciones. 


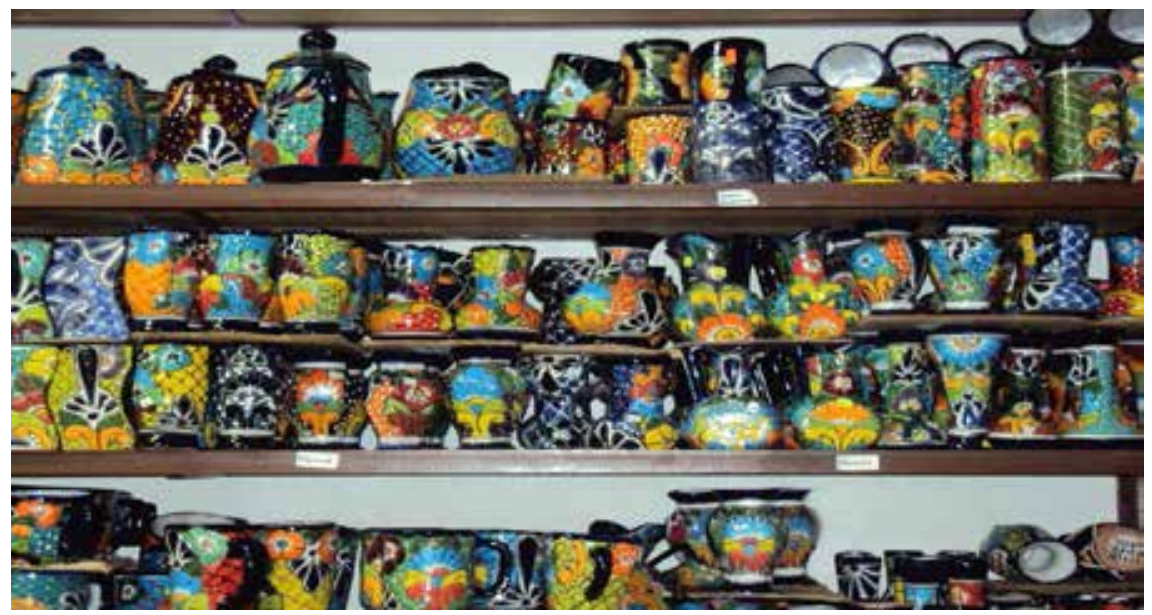

Fotografía 1. Alfarería de Dolores Hidalgo, Guanajuato. ${ }^{1}$

\section{¿Qué son las artesanías?}

Angelotti (2004), nos dice que encontrar una definición al concepto de artesanías no es una tarea sencilla, ya que una breve revisión bibliográfica nos puede advertir sobre las características desiguales, contradictorias o ambiguas de algunas definiciones. Probablemente es, como advierte Bartra (1998), al señalar que cuando hablamos de este tipo de creaciones nos enfrentamos a un problema no resuelto: el de los conceptos. Es esta filósofa quien expresa que el arte que producen los grupos indígenas generalmente no es denominado como arte popular, sino como arte primitivo $\mathrm{o}$ arte indígena. Desde sus planteamientos, ninguno de estos conceptos "arte popular", "arte primitivo", "artesanía" y "folklore" se usa con rigor y en ningún caso existe un consenso en cuanto su utilización para un mismo tipo de creación.

Autoras como Turok (1988), bajo una perspectiva antropológica, indican que entrar al mundo de las artesanías es descubrir un fenómeno tan complejo que trasciende, lo que, a primera vista, parecería ser su finalidad: bellos objetos utilitarios producidos por las manos. Indica también esta autora que las

1 Todas las fotos que aquí se presentan pertenecen al archivo personal de la autora, corresponden a diferentes visitas a comunidades y municipios caracterizados por su producción artesanal en el país. 
diferencias entre los objetos surgen a partir de la función que las ha visto nacer: lo cotidiano, lo ritual, lo ceremonial o lo decorativo. Para esta antropóloga, las implicaciones que tiene un objeto artesanal son muchas e interactúan entre sí; van desde el diseño hasta la situación (económica, social, tecnológica, etc.) en que se producen. Pedraza (2010), por su parte, indica que la proliferación de artesanías en la vida cotidiana pone de manifiesto su función comunicadora, el objeto portador de significación o mejor dicho, el objeto al que un individuo le asigna un valor, constituye un mensaje de la cosmovisión de un grupo cultural o de las riquezas naturales en una región determinada. Por otra parte, Fábregas y Santos (2000) defienden que la elaboración de artesanías no solo responde a una necesidad de identidad, de uso, costumbre o situación geográfica, sino que esta producción expresa también la habilidad creativa de los individuos y los contextos colectivos que conforman las expresiones culturales. Estas no son solo los rituales o las fiestas, sino la cotidianidad misma, las manifestaciones que día a día están presentes en la vida de un pueblo y que por ello, a veces, suelen pasar inadvertidas.
Por su parte, Pérez (2015) indica que artesanías: "se refiere al conjunto de productos u obras de arte, personalizadas, hechas por los artesanos como parte de su actividad ordinaria: obras, por tanto, habitualmente manuales, decorativas, por lo general de uso doméstico, hechas con toque artístico personal" (p. 47). Ese autor en El sentido de las artesanías en el concierto de la cultura (2015), indica que la artesanía es parte del sistema de comunicación de un pueblo que funciona como signo y es una de las características fundamentales de la cultura. El objeto es ocasión de contacto humano no solamente, sigue indicando este autor, porque los objetos son el centro de la actividad comercial, una actividad comunicativa por excelencia; sino en el sentido de que el objeto artesanal es el centro de la cohesión generacional por la cual la generación mayor hereda a la joven sus secretos y su saber ancestral.

Por ello defiende que las artesanías "son parte de procesos intensos de comunicación por los que se transmiten las tradiciones más íntimas de un grupo humano. Este es el sentido más profundo de las artesanías: reafirmar la tradición y asegurar la cohesión generacional" (p. 48). 
Así entendidas, las artesanías son un lenguaje por el cual los artesanos, al paso que construyen su tradición y educan a las generaciones jóvenes, se comunican entre sí, con la naturaleza y con los que los rodean. Es Köhler (2007), quien recordando la génesis del trabajo artesanal nos dice que su producción puede ser definida como la fabricación de una amplia gama de productos de distinta complejidad para un cliente individual, empleando herramientas y máquinas generales y flexibles por parte de una mano de obra cualificada. Para este autor, la principal característica diferencial de la producción artesana es la centralidad del hombre con sus cualidades y aptitudes individuales. Es un sistema de producción basado en relaciones sociales individualizadas entre cliente y fabricante, entre fabricante y proveedor, entre dueño y empleado. En lo que respecta a las artesanías mexicanas, se puede decir que estas, como indica Ramos (2010), han sido ampliamente tratadas desde tres líneas principales de interpretación. La primera es la artesanía vista como un objeto artístico, parte del patrimonio cultural y tradicional de los pueblos. Sobre esta tradición interpretativa existe una diversidad de estudios descriptivos sobre los objetos artesanales de las diferentes regiones del país y cuya proliferación y difusión se debe en mucho a las políticas estatales orientadas a la consolidación de la unidad nacional y al fomento del empleo rural y generación de divisas.

La segunda línea, indica esta autora, es la que se ubica desde la perspectiva antropológica marxista y que caracteriza a la producción artesanal familiar (la forma más común de producir artesanías en las áreas de escaso desarrollo industrial del país), como una actividad que es funcional para la acumulación privada de capital por la intermediación que ejercen los comerciantes mestizos mientras que los indígenas artesanos simplemente van reproduciendo su pobreza. Han sido recurrentes los enfoques que consideran que los artesanos indígenas no logran mejorar sus condiciones de vida porque la comercialización siempre es realizada por agentes mestizos que son los más beneficiados. El estigma social de "ser indio", subraya esta autora, es un factor clave que justifica la exclusión de vías para ascender en la formación económica y lograr riqueza (Littlefield, 1976; Novelo, 1976, 1993; Turok, 1988; Ramos, 2010). 
Una tercera orientación se encuentra en los estudios culturales que parten de la línea argumentativa neogramsciana y de la teoría de la reproducción, que consideran a las artesanías como manifestaciones de la cultura de las clases populares, resultado de la apropiación desigual del capital cultural, la elaboración propia de sus condiciones de vida y su interacción conflictiva con sectores hegemónicos (Ramos, 2010). Su enfoque considera no solo las limitaciones socioeconómicas estructurales, sino también las respuestas y formas de adaptación y resistencia de los pueblos mestizos y las comunidades tradicionales ante la dominación. Al tiempo de la reconversión económica macroestructural se produce la reconversión realizada por las propias clases populares que adaptan sus saberes y hábitos tradicionales (García Canclini, 1989). Novelo (1976) expone categorías distintivas de las artesanías, tales como: a) son artesanías aquellos objetos elaborados a mano, realizados por gente del interior, campesinos e indígenas (pero no necesariamente); b) siguen una tradición; c) son representativos de una cultura y d) son artesanías aquellos objetos realizados por artesanos. Es por eso que esta antropóloga explica que las artesanías tradicionales son aquellos bienes realizados por artesanos para el consumo doméstico o ritual, siendo objetos portadores de un valor histórico, cultural, utilitario o estético y cumplen una función socialmente reconocida, realizados por el artesano, individual o colectivamente, mediante técnicas simples. Mientras que por artesanos entiende a aquel individuo portador de una cultura, que mediante el dominio de una técnica predominantemente manual y con el apoyo de algunas herramientas primarias, transforma la materia con la finalidad de crear objetos socialmente útiles (Novelo,1976). Por su parte, organismos internacionales, como la UNESCO, a este respecto señalan que:

Los productos artesanales son los producidos por artesanos, ya sea totalmente a mano, o con la ayuda de herramientas manuales o incluso de medios mecánicos, siempre que la contribución manual directa del artesano siga siendo el componente más importante del producto acabado. Se producen sin limitación por lo que se refiere a la cantidad y utilizando materias primas procedentes de recursos sostenibles. La 
naturaleza especial de los productos artesanales se basa en sus características distintivas, que pueden ser utilitarias, estéticas, artísticas, creativas, vinculadas a la cultura, decorativas, funcionales, tradicionales, simbólicas y significativas religiosa y socialmente (Definición adoptada por el Simposio UNESCO/CCI "La Artesanía y el mercado internacional: comercio y codificación aduanera" - Manila, 6-8 de octubre de 1997).

Por su parte, la instancia encargada de la producción artesanal en México (Fondo Nacional para el Fomento de las Artesanías, FONART), propone la siguiente definición de artesanía:

Es un objeto o producto de identidad cultural comunitaria, hecho por procesos manuales continuos, auxiliados por implementos rudimentarios y algunos de función mecánica que aligeran ciertas tareas. La materia prima básica transformada generalmente es obtenida en la región donde habita el artesano. El dominio de las técnicas tradicionales de patrimonio comunitario permite al artesano crear diferentes objetos de variada calidad y maestría imprimiéndoles, además, valores simbólicos e ideológicos de la cultura local. La artesanía se crea como producto duradero o efímero, y su función original está determinada en el nivel social y cultural: en este sentido puede destinarse para el uso doméstico, ceremonial, ornato, vestuario, o bien, como implemento de trabajo. En la actualidad, la producción de artesanías se encamina cada vez más hacia la comercialización. La apropiación y dominio de las materias primas nativas hace que los productos artesanales tengan una identidad comunitaria $o$ regional muy propia, misma que permite crear una línea de productos con formas y diseños decorativos particulares que los distingue de otros (2014, p. 14).

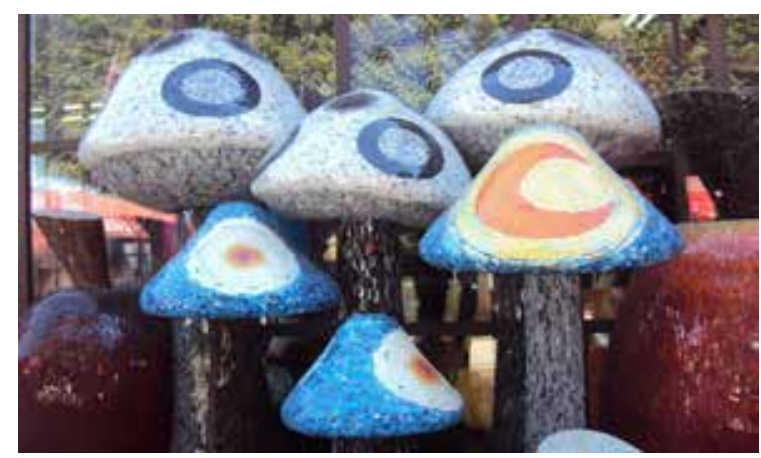

Fotografía 2. Producción de artífices de Tonalá, Jalisco. 


\section{- Estrategias mercadológicas e innovación... - Perla Shiomara del Carpio Ovando}

\section{Consumo de artesanías}

Como indica Turok (1988), al reba"tradicionales", "indígenas", o "popusarse los bienes necesarios para el lares" para señalar los atributos culconsumo familiar o comunitario, el intercambio resulta inevitable, como complemento a la agricultura y a la escasa ganadería que pueda existir en la zona. Quizá una de las mayores contradicciones de nuestros artesanos reside en el hecho de que entre más dependen de la artesanía en sus formas tradicionales de producción, más aumenta el riesgo de mantenerse en niveles paupérrimos y de miseria (Turok, 1988). Sea como fuere, los productos artesanales pertenecen a mundos diferenciados de consumo; por una parte encontramos objetos que desde la etapa desarrollista del capitalismo mexicano adoptaron el nombre de "artesanías", y a las que se ha hecho referencia como "típicas", turales dirigidos, unos, al consumo turístico, y otros, al consumo popular, especialmente campesino (Novelo, 2004).

Por otra parte, encontramos todo un repertorio de objetos relacionados a la vida cotidiana de las ciudades y de los pueblos, que proceden de los talleres de alfarería, carpintería, herrería, cerería, sastrería, zapatería, joyería, textiles, huarachería, cestería, etc., a los que no se les otorga el título de "artesanía mexicana", por su distancia de los mercados turísticos y de los círculos de comercio cultural, pero que tienen demandas locales y regionales que permiten su existencia y reproducción económica.

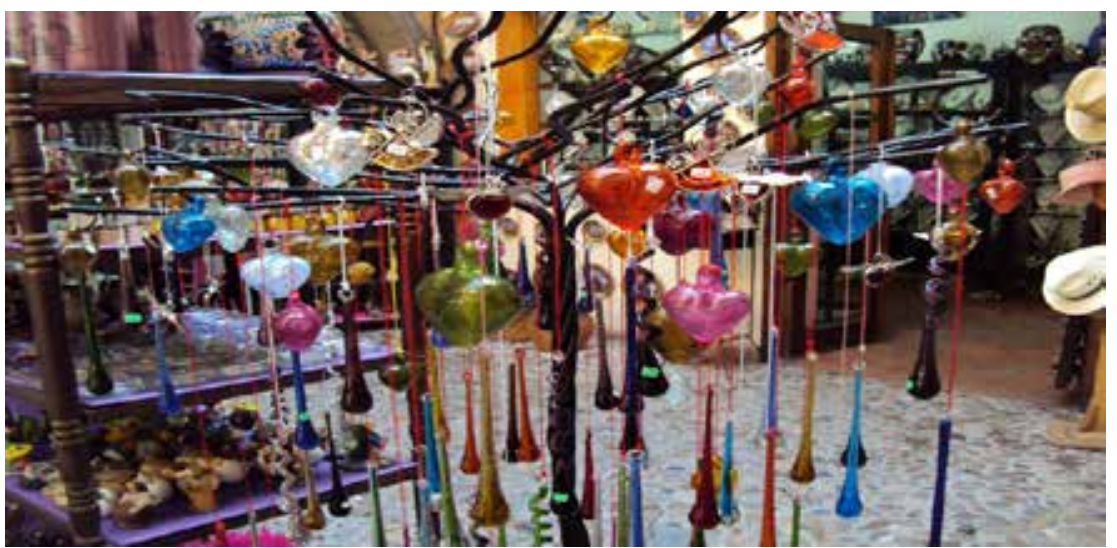

Fotografía 3. Artesanías de San Miguel de Allende, Guanajuato. 
Como parte de las llamadas culturas populares tradicionales, las artesanías se han reproducido transformándose en gran parte por el interés de los artesanos en mantener su herencia y renovarla al tiempo que obtienen ingresos, establecen relaciones externas y ganan prestigio (Ramos, 2010).

La moderna producción artesanal mexicana se distingue, pues, por la gran heterogeneidad y diversidad de sus productos, de sus formas de organización y relaciones sociales en el trabajo, distribución y consumo. En el siglo XXI, como advierte Ramos (2010), el gusto por y el consumo de las artesanías ha vivido múltiples transformaciones y su valoración ya no se restringe a los sectores "cultos que gustan del arte" y a los intelectuales que admiran y protegen nuestras raíces y ven en las artesanías manifestaciones de resistencia al capitalismo (Novelo, 1993). Además, como indica Turok (1988), las artesanías han sido clasificadas en cuatro categorías según el tipo de consumidor: para el turismo masivo dirigido, para decorar interiores, para el coleccionista y para la galería de arte.

Como indica Ramos (2010), en términos generales, en México, como en el resto de América Latina, la intensificación de la producción de artesanías ha sido resultado principalmente de tres situaciones: 1). Las condiciones de crisis de las familias campesinas ante la disminución del territorio de las comunidades, el aumento de la población y los efectos de las políticas públicas de abandono a este sector, al mismo tiempo de la creciente dependencia de insumos agrícolas industriales promovidos por los programas oficiales; 2). Las motivaciones para consumir artesanías de algunos sectores de la población como medio para afirmar identidades o distinguirse por el gusto refinado y tradicional; 3). La promoción gubernamental con los fines de crear empleos que disminuyan la emigración, fomentar la exportación, atraer turistas y como parte de una política que usa lo popular para consolidar la unidad nacional bajo la forma de un patrimonio que parece trascender las divisiones entre clases y etnias (García Canclini, 1982).

Los trabajos de Good Eshelman (1988), Stephen (1990) y Clements (1988) dan cuenta de diferentes contextos de América Latina y de México, y muestran que, a través de su participación en el mercado, 
los pueblos artesanos han mantenido y reforzado su identidad étnica al mismo tiempo que desarrollan su capacidad de adaptación, lo que ha permitido mantener y renovar su cultura y mejorar sus condiciones de vida. Sin embargo, las interpretaciones anteriores no coinciden, como indica Ramos (2010), con los enfoques que tienen sobre este tema investigadoras como Novelo (1976) y Arizpe (1986). La primera considera que los artesanos indígenas no logran mejorar sus condiciones de vida mediante este tipo de producción familiar de artesanías, porque la comercialización siempre es realizada por agentes mestizos que son los más beneficiados. Mientras que Arizpe (1986) considera que el estigma social de "ser indio" es un factor clave que justifica la exclusión de vías para ascender en la formación económica y lograr riqueza. Sea como fuere, podemos aquí decir que las artesanías desempeñan un papel múltiple y cada objeto enfrenta una situación particular.

\section{Tipologías y usos}

De acuerdo con lo señalado en el apartado anterior, la calidad de artesanía se confiere a un producto plástico por provenir de un proceso de trabajo fundamentalmente manual y calificado en relación con los patrones industriales (Novelo, 2002). Así, el artesano -como buen conocedor y especialista de un oficio que se desarrolla históricamente antes de la industria- puede producir objetos artísticos, pero no necesariamente; puede también producir objetos en serie a los que no adjudica ningún valor socialmente establecido como estético. Pero, como indica la autora señalada, dependerá esto de las condiciones generales de su producción.

En el caso de las artesanías mexicanas se puede decir, como lo hace Novelo (2002), que se elaboran en forma artesanal una serie de objetos sin ninguna intencionalidad estética ya sea porque la industria no los ha incorporado a su producción o porque las condiciones de subdesarrollo reproducen sistemas de trabajo arcaicos que por su inversión social puede producir a bajos precios objetos para los consumidores más pobres. Y hay, por otra parte, objetos que la sociedad considera y califica como artísticos y que también requieren en su elaboración el desarrollo de las habilidades artesanas.

Las formas de producción de artesanías son, pues, muy variadas 
conforme a la fuerza de trabajo empleada, los medios de producción, el grado de división del trabajo en los oficios, los ciclos de trabajo, la productividad, las fuentes de financiamiento, el volumen de producción, su comercialización y su destino (Novelo, 1997). Las formas que pueden denominarse o que se consideran como las más "atrasadas" por su base técnica son la familiar y el taller individual, ambas se pueden observar como predominantes en la República Mexicana. Estas, generalmente, son formas de trabajo que permiten solamente la sobrevivencia de la familia; es debido a eso que aunque los ingresos son escasos, los productores consumen no solo los medios de vida indispensables, sino también otros que ofrece el mercado de producción industrial, incluidas las materias primas que utilizan para realizar sus artesanías. La práctica de la forma familiar de producción es propia de las zonas o comunidades rurales y de la producción indígena, particularmente en lugares de poco desarrollo industrial. En términos generales, podríamos decir, siguiendo a Novelo (1976), que son cuatro las formas predominantes de producción artesanal: la forma familiar, el pequeño taller individual, el taller con obreros y la manufactura. Indica esta antropóloga detalles respecto a estos tipos de talleres:

1). Familiar: este modelo es representativo de las artesanías tradicionales realizadas en las zonas rurales en las cuales las herramientas pertenecen al productor, quien dispone de los recursos mínimos para lograr reiniciar un nuevo ciclo productivo; 2). Taller individual: es el más cercano al modelo del artesano medieval, donde se trabaja por encargo y cuyo volumen de producción está indisolublemente unido a la habilidad y al ritmo que el artesano le imprime a su labor; 3) El taller: en este espacio con trabajadores el proceso de trabajo lo dirige el dueño del taller, quien, además, participa en las actividades y es, en términos generales, maestro de oficio; 4) La manufactura: se caracteriza por una organización de trabajo que reúne en un mismo taller a obreros especialistas en operaciones parciales del proceso total de trabajo y donde el dueño asume el rol de administrador de la empresa sin intervenir en las operaciones laborales, aunque puede tener injerencias en el diseño de los productos (Novelo, 1976). Grosso modo, en dichos 
espacios es donde se producen los objetos artesanales mexicanos. Conviene ahora reflexionar respecto a algunos retos que enfrentan quienes en el país se dedican a realizar artesanías y sobre algunas vertientes de apoyo en la que apuestan instancias interesadas en los integrantes del gremio y en sus productos.

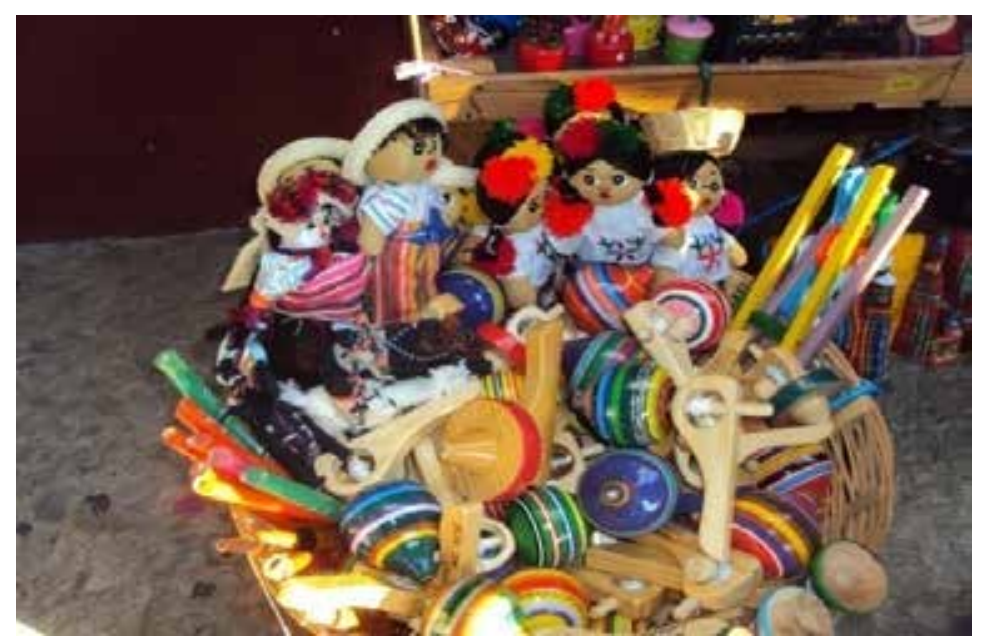

Fotografía 4. Juguetes artesanales. Chiapa de Corzo, Chiapas.

\section{Retos que enfrenta el sector artesanal y vertientes de apoyo}

En México la instancia interesada en la producción artesanal y sus artífices es el Fondo Nacional para el Fomento de las Artesanías (FONART)²,

2 El Fondo Nacional para el Fomento de las Artesanías (FONART) es un Fideicomiso Público del Gobierno Federal, sectorizado en la Secretaría del Desarrollo Social, encargado de apoyar a los artesanos de la República Mexicana en diferentes dimensiones, tales como: capacitación integral y asistencia técnica, apoyos a la producción, adquisición de artesanías, apoyo a la comercialización y organización de concursos. Mayores detalles se pueden consultar en: www.fonart.gob.mx Respec-

institución gubernamental con programas dirigidos a los artesanos y a sus productos. Aunque hasta el momento no se cuente con un censo global de todos los artesanos en el país,

to a los padrones de artesanos que aquí se analizan de dicha institución, conviene advertir que las estimaciones corresponden al primer semestre de 2010 y fueron proporcionados electrónicamente a través de INFOMEX, en el mes de junio de dicho año. Las solicitudes de acceso a la información pública se realizaron a través de la página: www.infomex.org.mx 
una fuente posible -para conocer las ramas artesanales y la cantidad de artesanos en cada una de ellas-, son los registros que tiene esta instancia de los artífices apoyados en sus diferentes vertientes ${ }^{3}$. He aquí que se presentan las áreas en la que se encaminan las acciones que esta instancia emprende para apoyar a los artesanos y a sus elaboraciones.

\section{1.- Capacitación integral y asisten-} cia técnica: la capacitación integral tiene por objeto coordinar y administrar un proyecto enfocado al mejoramiento de la condición productiva y comercial de las y los artesanos, mediante la transmisión de conocimientos en organización, materias primas, proceso productivo, comercialización, informática, administración, salud ocupacional, aspectos jurídicos y de aprovechamiento sostenible, así como en el desarrollo de certificación en competencias laborales.

Son, pues, diversas las dimensiones en la que los integrantes del gremio necesitan fortalecer sus conocimientos y habilidades. Es de

3 Información obtenida de la página de internet del Fondo Nacional para el Fomento de las Artesanías hitps://www.fonart. gob.mx/web/index.php/programas-sociales especial interés que la aplicación de estos represente mejoras para este sector y les facilite aspectos tales como la ejecución de su oficio, la adquisición de materias primas (compra, uso sostenible de los recursos), el cuidado de su salud, asesoría en comercialización (marketing, uso de nuevas tecnologías que permita difundir de diferentes maneras y en diferentes mercados sus productos: exportación, por ejemplo), asuntos jurídicos (propiedad intelectual, derechos de autor, contratos, convenios, otros), y aspectos relacionados con la calidad (certificación en diferentes competencias, otros).

Entre los retos del oficio también destaca la disminución preocupante de ciertas materias primas que sirven de base para la producción artesanal. Además, la promoción del turismo (interno y externo) ha generado la creación y multiplicación de empresas dedicadas a la compra y venta de artesanías, por lo cual muchos talleres tradicionales se han visto en la imperiosa necesidad de modificar su lógica de producción para atender a una mayor demanda y mayor escala. Cabe señalar que también es importante fortalecer capacitación en cuanto al diseño de las artesanías, pues puede ser una 


\section{- Estrategias mercadológicas e innovación... - Perla Shiomara del Carpio Ovando}

herramienta para adaptar la producción al mercado, sin embargo, es necesario replantear los planes y programas, profesionalizando y formando primero a los diseñadores que acuden a las comunidades con base en un código de ética, dado que lo más común es que, por estatus social y formación, los diseñadores tienen mayor posibilidad de conocer diferentes mercados (Turok, 2015). Es necesario que estos realicen tareas conjuntas con los artesanos (con quienes realizan textiles, por ejemplo). Véanse en el siguiente esquema las áreas en las que Fonart proporciona capacitación a los artesanos y a las artesanas del país.

Esquema 1. Áreas en las que Fonart brinda capacitación

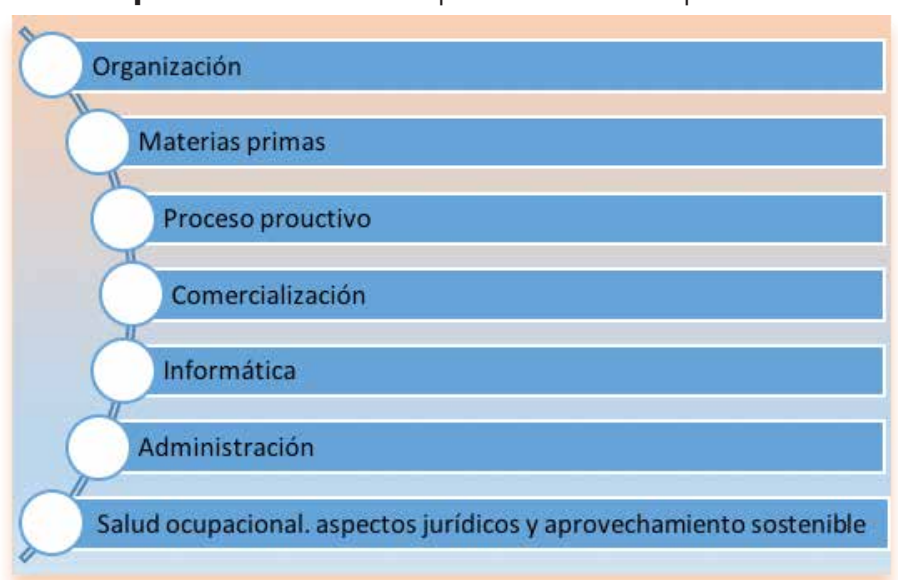

Fuente: elaboración propia a partir de información obtenida en https://mww.fonart.gob.mx/web/index.php/programas-sociales

2.- Apoyos a la producción: Esta vertiente apoya a las y los artesanos con recursos económicos y/o en especie para fortalecer la adquisición de activo fijo y/o insumos destinados a la producción artesanal. En este rubro se señala que "no se financiará en ningún caso mano de obra, pago de salarios ni gastos de administración”.

Como se ha observado en diferentes comunidades artesanales, quienes se dedican a la producción artesanal enfrentan múltiples retos y dificultades que tienen que ver, sobre todo, con la comercialización de los productos, los precios bajos de estos, la competencia con productos industriales e importados y la situación precaria de los productores. Aunado a estos se encuentra el poco reconocimiento social del oficio, el 
impacto del oficio en la salud de los artesanos y la discriminación o exclusión que viven los integrantes del gremio; este tema es aún más complicado si hablamos de artesanos indígenas.

Existe, especialmente entre los artesanos que no se encuentran organizados o realizan su producción de manera independiente y comercializan su producto en la comunidad o en lugares próximo a ellas, un desconocimiento respecto a programas de apoyo, capacitación y financiamiento para los integrantes del gremio. En las comunidades lejanas, por ejemplo, los artesanos tienen poco acceso, en ocasiones, a medios de comunicación o a tecnologías de información (como internet), para obtener información de diferentes temáticas, en general, y de apoyos al sector, en particular. ${ }^{4}$

4 Recordamos que en 2010 personal de la Casa de las Artesanías de Chiapas señalaba que una de las dificultades que tenían era compartir la información de sus programas a los artesanos que vivían en comunidades donde los caminos de terracería les dificultaban el acceso para aproximarse a ellos y donde la señal telefónica o el internet era difícil, lo cual generaba pocas posibilidades de comunicación con los habitantes del lugar (sabemos que esta dificultad en el acceso no puede ser pretexto para que las instancias se acerquen a las comunidades y atiendan las necesidades de su población)
3.- Salud ocupacional: Las actividades propias de esta vertiente se encaminan a reducir la incidencia de las enfermedades y accidentes derivados de la actividad artesanal, así como a fomentar un estilo de vida y ambientes de trabajo saludables.

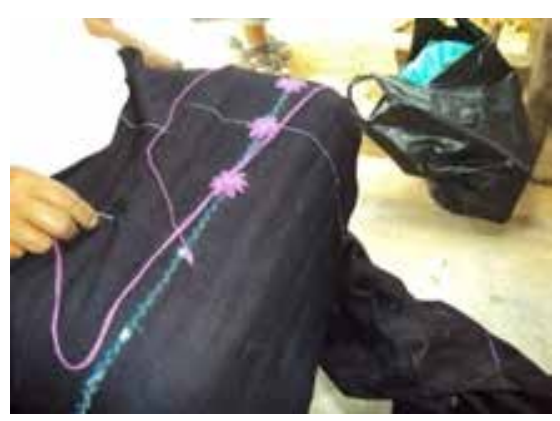

Fotografía 5. Artesana bordando detalles en una falda para uso personal. Simojovel, Chiapas.

En múltiples trabajos (Del Carpio, 2012; Del Carpio y Freitag, 2013), se ha señalado que cada oficio demanda esfuerzo que con el paso de los años afectan la salud de sus artífices. Los alfareros, por ejemplo, con el paso del tiempo sufren afectaciones en las vías respiratorias por el humo de los hornos; las mujeres que elaboran textiles llegan a tener dificultades visuales por el esfuerzo y la concentración que implica la elaboración de sus tejidos; los dolores de espalda (por la postura en la ejecución del oficio) son frecuentes y el malestar en las manos 


\section{- Estrategias mercadológicas e innovación... - Perla Shiomara del Carpio Ovando}

es también común. Es importante prestar especial atención en el uso de materiales, utensilios y herramientas de trabajo y las condiciones ergonómicas que propicien que los artesanos y las artesanas procuren su salud en el desarrollo de su trabajo, aunque la apuesta también sería emprender acciones de prevención del cuidado de la salud.

\section{4.- Apoyos para impulsar la comer-}

cialización: en esta modalidad Fonart beneficia a las y los artesanos en forma individual por medio de la compra de su producción artesanal hasta por $\$ 15.000$ (quince mil pesos $00 / 100$ M.N.) al año.

En este sentido, observamos la necesidad que tienen los artesanos de comprender la dinámica del mercado, en especial el comportamiento de los consumidores y competidores, esto es vital para que un negocio tenga éxito. Esto es así porque resulta relevante que antes de elaborar un producto primero se identifique su demanda. Es allí donde resulta importante el marketing, el cual "presupone un enfoque impulsado por el mercado y centrado en el consumidor. Esta es la realidad para la mayoría de categorías de bienes y servicios" (Centro de Comercio
Internacional UNCTAD/OMC y Organización Mundial de la Propiedad Intelectual, 2003, p. 3). Dicha fuente indica que si los artesanos $y$ artistas quieren conseguir una remuneración justa de su creatividad en el mercado deben, entonces, aplicar una estrategia de marketing planeada y sistemática, como lo han llegado a realizar algunos artesanos considerados artistas.

\section{5.- Apoyos para la promoción arte-} sanal en ferias y exposiciones: esta vertiente beneficia a las y los artesanos con recursos económicos destinados a gastos de viaje para asistir a espacios y eventos artesanales, así como material gráfico publicitario, renta, construcción o acondicionamiento de espacios comerciales.

Que Fonart apoye en este sentido a los artesanos resulta valioso, pues si señalamos que los ingresos que generalmente el artesano recibe por sus productos no compensa el esfuerzo ni el tiempo invertido en la elaboración de sus artesanías, es todavía más desalentador si consideramos que con esos ingresos (obtenidos por la comercialización de sus artesanías), tiene también que pagar el uso de suelo por exponer en tianguis, expos o ferias de artesanías. 
Además, las ventas no son siempre seguras. La venta de artesanías está siempre realizándose en un ambiente de incertidumbre. Lo mismo vale para quienes se convierten en nómadas para buscar compradores a sus productos, esto representa un problema y los expone a accidentes, a las inclemencias del tiempo (lluvia, calor) y a diferentes afectaciones de su salud (deshidratación, resfriados, dolores musculares por transitar las arterias de los lugares que visitan buscando compradores a sus productos, otros). ${ }^{5}$

\section{6.- Concursos de arte popular: con} las acciones de Fonart en esta vertiente reconoce a las y los artesanos, independientemente de su nivel de ingreso, de las diferentes regiones y centros productores del país, que se distinguen por la preservación, rescate o innovación de las artesanías, así

5 Respecto a las principales dificultades del sector puede consultarse: Sedesol (2015). Diagnóstico del programa del Fondo $\mathrm{Na}$ cional para el Fomento de las Artesanías. Recuperado de: http://www.gob.mx/ cms/uploads/attachment/file/32059/ Diagnostico_FONART_1_-1-40.pdf Importante también resulta consultar: Sedesol (2015). Diagnóstico de la capacidad de los artesanos en pobreza para generar ingresos sostenibles. Recuperado de: http: / / www.gob.mx/cms/uploads/attachment/ file/32043/Diagnostico_FONART_3_. pdf como aquellos que mejoran las técnicas de trabajo y recuperan el uso y aprovechamiento sostenible de los materiales de su entorno natural (Fonart, 2016).

Para permanecer y coexistir con otras formas de producción, los artesanos han tenido que reinventarse, apostarle a la innovación e ir conquistando nuevos mercados. Aunque no es lo constante, cada vez observamos el trabajo de artesanos que han adquirido el reconocimiento de artistas y exponen sus productos en galerías y tiendas de exhibición. Para Fonart ha resultado importante el rescate y difusión de técnicas que fomenten el cuidado del ambiente y el uso sostenible del entorno natural en las artesanías.

En términos generales, estas son las vertientes en las que esta instancia apoya a los integrantes del gremio y a sus elaboraciones; pueden verse también en el siguiente esquema: 


\section{- Estrategias mercadológicas e innovación... - Perla Shiomara del Carpio Ovando}

Esquema 2. Vertientes de apoyo a los artesanos y a sus productos

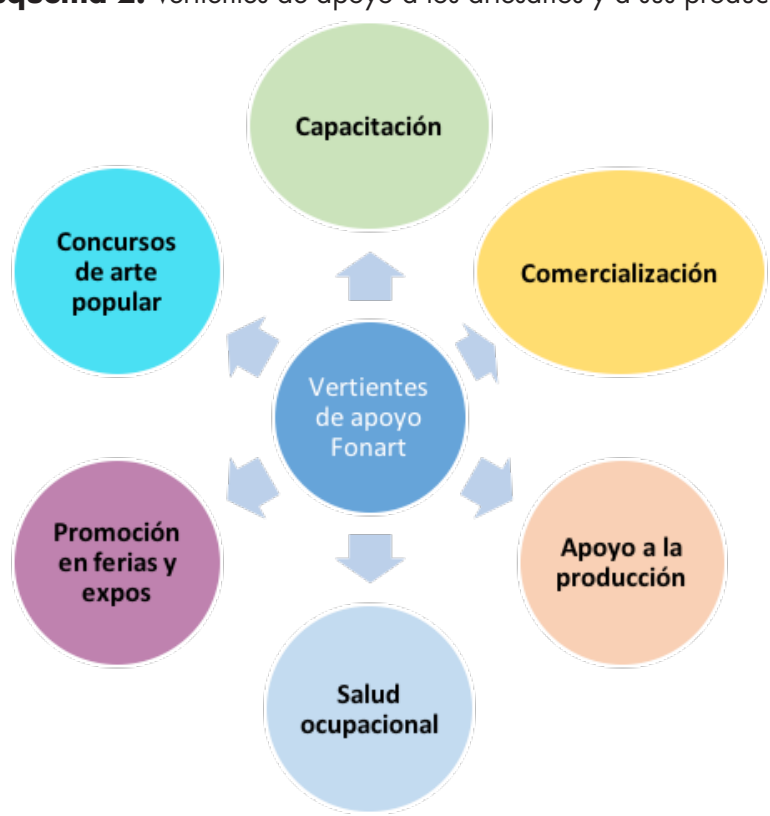

Fuente: elaboración propia a partir de información obtenida en https://www.fonart.gob.mx/web/index.php/programas-sociales

Los logros obtenidos en las integrador. Por eso León (2009), deseis vertientes en las que esta ins- fiende que el desarrollo es la consetancia apoya a los artífices y a sus cución del buen vivir de todas las productos, sin duda, aunque no personas, en paz y armonía con la son suficientes ni benefician a to- naturaleza y los demás seres vivos, dos los artesanos que hay en el país, y la prolongación indefinida de las son de reconocerse dado que per- culturas urbanas. El buen vivir, conmite ir apuntalando mejoras para tinúa señalando el autor, presupone los integrantes del gremio, pues si que las libertades, oportunidades, se atienden estas áreas este sector capacidades y potencialidades reaquizá puede aspirar a concebir un les de los individuos se amplíen de desarrollo más amplio y no solo ba- modo que permitan lograr simultásado en el crecimiento económico; neamente aquello que la sociedad, un desarrollo tanto humano, como los territorios, las diversas identisocial, político, económico, am- dades colectivas y cada uno valora biental y cultural, más incluyente e como objetivo de vida deseable. En 
este sentido, se necesitan establecer políticas de desarrollo que consideren no solo un desarrollo económico y descentralizado, sino que tome en cuenta otros aspectos que también resultan significativos para este sector (Mandujano, Del Carpio y Martínez, 2016).

Por eso Boisier (1999) propone apoyarse en el concepto de capital sinergético para potenciar y articular nuevas formas de capital, casi todas de carácter intangible, a fin de colocar un territorio en el sendero virtuoso del desarrollo. Se trata de cuestiones cognitivas, simbólicas, culturales, sociales, cívicas, etcétera, que parecen vincularse más estrechamente a una contemporánea concepción del desarrollo que va más allá de la construcción de infraestructura $u$ otras acciones materiales, pues, como señalan Mateus y Brasset (2002), el grado de desarrollo se mide de acuerdo con indicadores de actividad económica que no tienen necesariamente que ver con el beneficio que brinda al ser humano, con las señales de bienestar humano o con las complicaciones de cualquier tipo, principalmente de salud que pueda acarrear esta manera de impulsar el crecimiento en los países.

\section{Algunos ejercicios y resultados}

Con el objetivo de conocer más detalles de las ramas artesanales del país, cuyos elaboradores están registrados en los concentrados de Fonart, se realizaron algunos ejercicios con información que esta institución proporcionó por medio de Infomex (en el año 2010, con datos del primer semestre de ese año y de 2009, año completo). ${ }^{6}$ Actualmente, son seis las vertientes donde Fonart apoya a los artesanos y a sus productos, sin embargo, para el periodo señalado (datos de 2009 y 2010) eran cuatro las vertientes: a). Apoyo en materia prima; 2). Cursos de capacitación; 3 ). Acceso y canalización a microcréditos, y d). Oportunidad y apoyo para participar en expo-ventas nacionales que permitieran dar a conocer y vender los productos artesanales. Actualmente, tal como vimos en el apartado anterior, aparte de las vertientes anteriores también están incluidas el

\footnotetext{
6 Respecto a los padrones de artesanos que aquí se analizan, conviene advertir que las estimaciones corresponden al primer semestre de 2010 y de 2009, fueron proporcionados electrónicamente a través de INFOMEX del Instituto Nacional de Transparencia, Acceso a la Información y Protección de Datos Personales, en el mes de junio de dicho año (2010). Las solicitudes de acceso a la información pública se realizaron por medio de la página: www. infomex.org.mx.
} 
área de salud y los concursos de arte popular.

Para realizar este "buceo" de la situación artesanal en aquel momento, como estrategia metodológica de obtención de información se acudió a la investigación cualitativa documental. Las fuentes de información fueron los registros de Fonart correspondientes al primer semestre de 2010 y todo el 2009, datos correspondientes a los artesanos y artesanas que en el país participaban en las cuatro vertientes en los que apoyaba, en ese momento, dicha instancia. Además, se tomó también como fuente una serie de documentos oficiales entorno a la producción artesanal y material documental y bibliográfico respecto a la producción artesanal y a sus artífices.

Estos ejercicios permitieron señalar que en el primer semestre de 2010 las estimaciones proporcionadas por dicha institución reportaron a un total de 4.207 artesanos registrados (3.291 mujeres y 916 hombres) en su padrón nacional. En dicho año, al igual que en el año 2009, ${ }^{7}$ la producción de textiles llevó la batuta al ser la rama artesanal con la mayor cantidad de registros, al tener 2.228 artesanas. En segundo lugar se encontraron los artesanos en la categoría de "varios" (1.010 artesanos); en esta no se especificó la rama artesanal a la que se dedicaban los allí registrados. En un tercer lugar se ubicaron los artesanos dedicados a la elaboración de productos con maque y laca (261 artesanos); fue esta rama la que ligeramente desplazó a la alfarería que en el 2009 había sido la rama artesanal que se posicionó en segundo lugar, pues en 2010 esta fue desplazada al cuarto lugar al tener 249 artesanos registrados. Las ramas artesanales con menor cantidad de registros fueron: instrumentos musicales (1 artesano), talabartería (9 artesanos) y pintura (12 artesanos). Esto se puede visualizar en el gráfico siguiente:

7 Mientras en 2009 se reportaron 10.352 artesanos, en 2010 fueron tan solo 4.207 artesanos registrados. Esto fue así porque los datos de 2010 corresponden tan solo

al primer semestre, no al año concluido, y las correspondientes a 2009 pertenecen al año completo. 
Gráfico 1. Artesanos beneficiados por Fonart en 2010

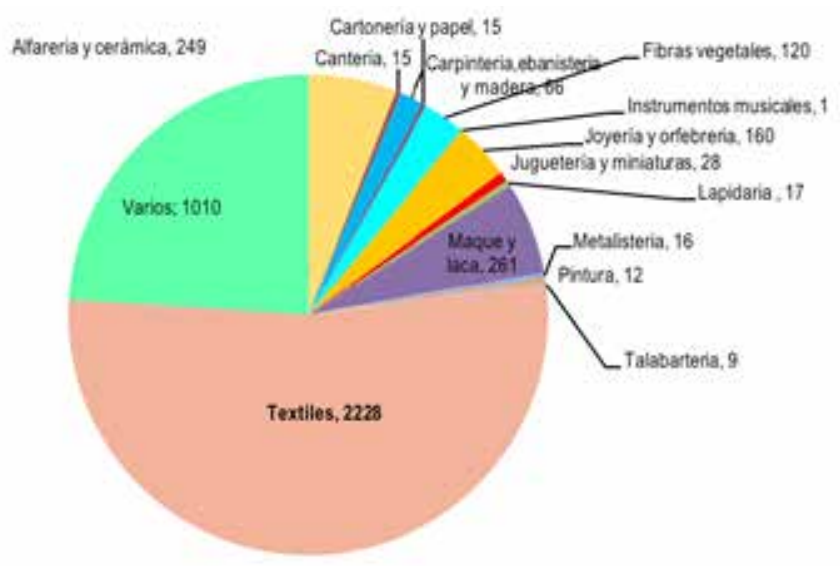

Fuente: elaboración propia a partir del padrón de artesanos proporcionados por Fonart. Datos correspondientes al primer semestre de 2010.

Respecto a la cantidad total en comparación con los registros de (4.207 artesanos) por sexo, el padrón los hombres (152 artesanos). Suceindicó que en ese año (2010) hubo dió lo mismo en la categoría de "vamayor cantidad de mujeres registra- rios" (701 artesanas superaron los das (3.291 artesanas), en compara- datos de 309 hombres). En la rama ción a los registros de los hombres de maque y laca también las muje(916 artesanos). Como se ha dicho res llevaron la batuta (165 artesanas antes, en el primer semestre de 2010 superaron los registros de 96 artesala producción de textiles fue nueva- nos). En el trabajo con fibras vegetamente la rama con mayor número les también los registros de mujeres de registros a nivel nacional (2.228 (81 artesanas) fueron mayores que artesanos), allí llevaron el protago- el de los hombres (39 artesanos). nismo las mujeres (2.076 artesanas), 


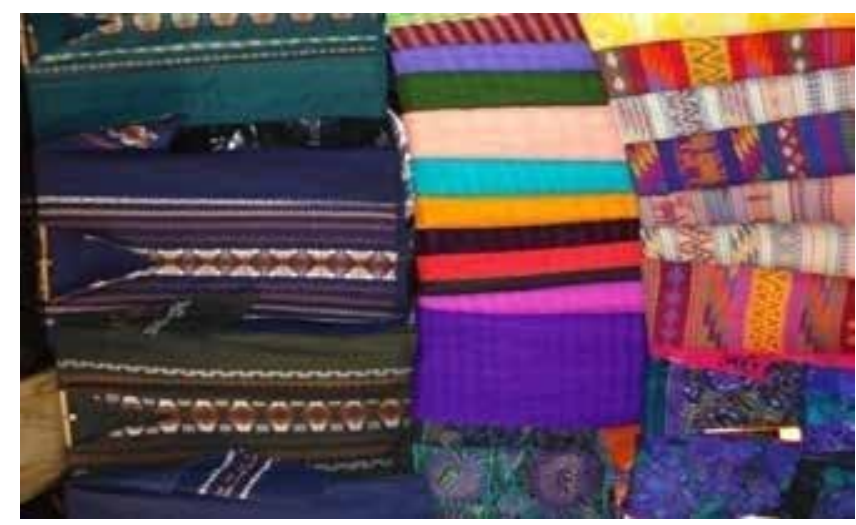

Fotografía 6. Textiles realizados por mujeres de Zinacantán, Chiapas.

Las ramas artesanales donde correspondiente a 2010 también relos hombres mostraron mayor nú- portó a 20 estados de la república de mero de registros fueron: joyería y México como entidades de donde orfebrería (100 artesanos supera- eran originarios los artesanos emron los registros de 60 artesanas), padronados. La cantidad perteney carpintería, ebanistería y talla de ciente a cada uno de ellos fue la que madera (45 artesanos superaron el muestra el gráfico siguiente: registro de 21 artesanas). El padrón

Gráfico 2. Artesanos beneficiados por estado de la república de México. Fonart, 2010

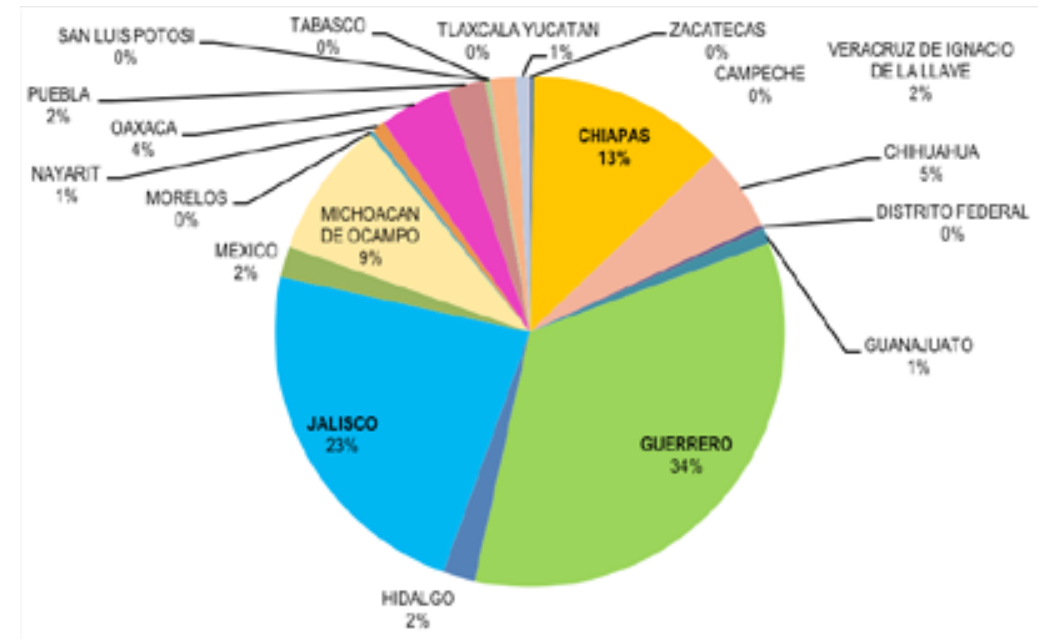

Fuente: elaboración propia a partir del padrón de artesanos proporcionados por Fonart. Datos correspondientes al primer semestre de 2010 
Tal como se observa, los estados de donde eran provenientes la mayor cantidad de artesanos en el país, según estas estimaciones (primer semestre 2010) fueron: Guerrero (1.435 artesanos), Jalisco (965 artesanos), Chiapas (532 artesanos) y Michoacán (368 artesanos). Los estados con menos registros fueron: Tabasco (1 artesano), Tlaxcala (1 artesano), Zacatecas (3 artesanos) y Campeche (10 artesanos).

En varios de estos estados (con mayores registros de artesanos que han recibido apoyo en diferentes vertientes), podemos observar la presencia de población indígena, y si elegimos, por ejemplo, al estado de Chiapas, podremos conocer algunas de las ramas artesanales a la que se dedican sus hacedores, lo cual resulta ilustrativo. En este estado del sureste mexicano (Chiapas), para ese año, por ejemplo, se reportó a 532 artesanos (475 mujeres y 57 hombres), y las actividades con mayor cantidad de registros fueron: la elaboración de textiles (436 artesanos: 426 mujeres y 10 hombres), maque y laca (28 artesanos: 18 mujeres y 10 hombres), y joyería y orfebrería (20 artesanos: 14 mujeres y 6 hombres). En las tres ramas fueron las mujeres quienes tuvieron mayor cantidad de registros en comparación con los datos correspondientes a los hombres. La cantidad de ambos en cada rama artesanal se detallan en el contenido de la tabla siguiente:

Gráfico 3. Hombres y mujeres, por rama artesanal, apoyados en Chiapas por Fonart, 2010

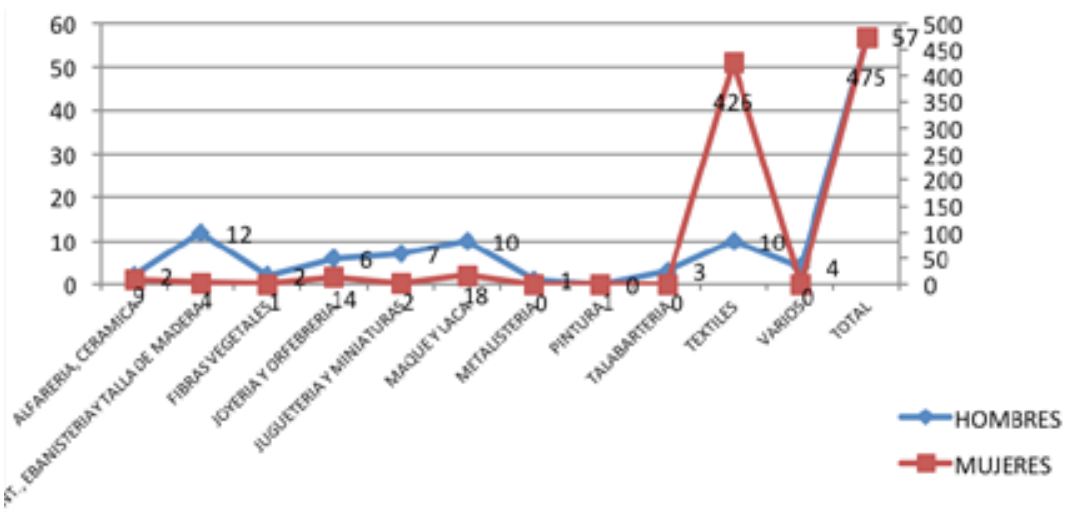

Fuente: elaboración propia a partir de datos proporcionados por Fonart, 2010. 


\section{- Estrategias mercadológicas e innovación... - Perla Shiomara del Carpio Ovando}

Como se observa, las ramas artesanales que tuvieron menos registros de artesanos originarios de Chiapas fueron: metalistería (1 artesano), pintura (1 artesana) y talabartería (3 artesanos). Quizá deberíamos ser más críticos con las cifras aquí presentadas. Fonart es solo una fuente posible y probablemente tiene muy pocos artesanos registrados (consideramos necesario hacer este mismo ejercicio con datos recientes). A nivel estatal, son los institutos de las artesanías o casas de cultura quienes cuentan con padrones o registros de la cantidad de personas que se dedican a las diferentes ramas artesanales. A quienes están "empadronados" se da seguimiento y apoyo, mientras que el trabajo de los que no figuran en estos listados queda en el anonimato.

Poco se sabe de aquellos artesanos cuyos datos no aparecen en un censo, en un papel, en algún lugar. Sea como fuere, nuestro argumento es que, en vez de ver a estos documentos y estadísticas oficiales apenas como fuentes de información, deben verse, considerarse y tratarse como productos sociales; deben ser analizados y no empleados meramente como instrumentos. Hay que "considerarlos como un recurso y no como un tópico de estudio, (ya que esto) significa utilizar el trabajo interpretativo e interaccional que está incluido en su producción, tratarlos (pues) como un reflejo o documento de los fenómenos que están detrás de su producción" (Hammersley y Atkinson, 1994, p. 153).

Lo que se quiere señalar aquí es que se considera importante reparar en el hecho de que en México no tenemos un registro global de la cantidad de artesanos que hay en el país, lo cual "nos dice" mucho respecto al lugar que este sector productivo tiene en la economía nacional y nos habla también de su poco reconocimiento y prestigio social (aunque resulta también necesario dirigir la mirada a los datos que INEGI puede proporcionar en sus censos de población respecto a este sector, en algunas de sus variables).

Lo dicho hasta ahora, respecto a los registros analizados, nos permite saber que México es un país de artesanos de orígenes étnicos diversos y es también un país donde sobresale un amplio abanico de ramas artesanales, siendo la producción de textiles la que tiene en la república de México la mayor cantidad de artesanos registrados en Fonart. 
En esta, y en otras ramas artesanales, las mujeres muestran protagonismo; por lo menos eso es lo que nos dejan saber los datos aquí analizados y que brevemente se pueden resumir en la siguiente tabla.

Tabla 1. Cantidad de artesanos apoyados por Fonart en 2009 y 2010

\begin{tabular}{|c|c|c|c|c|c|}
\hline Año & Periodo reportado & Hombres & Mujeres & Total & Rama predominante \\
\hline $\mathbf{2 0 0 9}$ & Año concluido & 2.711 & $\mathbf{7 . 6 4 1}$ & $\mathbf{1 0 . 3 5 2}$ & Textles \\
\hline $\mathbf{2 0 1 0}$ & Primer semestre & 916 & $\mathbf{3 . 2 9 1}$ & $\mathbf{4 . 2 0 7}$ & Textiles \\
\hline
\end{tabular}

Fuente: elaboración propia a partir de los datos analizados.

Desde esa reflexión y desde dichos datos, quizá no sea tan atrevido decir que: las artesanías en México están mayoritariamente entre las manos de las mujeres. ${ }^{8}$ Esta afirmación, aunque corresponde al análisis realizado con información de 2009 y 2010 de Fonart, sigue vigente, pues esta misma instancia en Porcentaje de artesanos beneficiados por el programa Fonart, distribuidos por sexo (2016), nos recuerda que tiene como objeto atender a los artesanos $\mathrm{y}$ artesanas a fin de promover, reconocer y dar a conocer la importancia y riqueza social y cultural de la actividad artesanal a nivel nacional e internacional, contribuyendo así a

8 Importante sería tratar de conocer si estos datos siguen siendo constantes para este año que transcurre. su desarrollo socioeconómico. Y señala que durante los últimos años ha incrementado la población que esta instancia ha atendido, la cual, con relación a mujeres y hombres ha presentado un comportamiento promedio de atención que señala que del $100 \%$ de los beneficiarios, el $70 \%$ son mujeres y el $30 \%$ son hombres. Este indicador también intenta abonar al eje transversal de perspectiva de género del Plan Nacional de Desarrollo (2013-2018), intentando dar atención a mujeres con principio de equidad. Señala también esta instancia que el porcentaje de mujeres atendidas es alto, ya que los apoyos que otorgan son destinados principalmente a ramas artesanales como son la producción de textiles y fibras vegetales que, en su gran mayoría, son protagonizadas por mujeres. 


\section{- Estrategias mercadológicas e innovación... - Perla Shiomara del Carpio Ovando}

Lo anterior, indica esta fuente, tiene como fundamento el Diagnóstico del Programa del Fondo Nacional para el Fomento de las Artesanías, elaborado por la Secretaría de Desarrollo Social en 2014 (señalado en Fonart, 2016), documento que indica que: "Las ocupaciones con mayor porcentaje de artesanos por debajo de la línea de bienestar son: los bordadores y deshiladores (78\%), los trabajadores en la preparación de fibras e hilados (74\%) y los artesanos(as) de productos de bejuco, vara, palma, carrizo y mimbre".

\section{Posibles acciones}

Fonart ha emprendido acciones que apoyan a los artesanos y a las artesanas que en México han recurrido a esta instancia para acceder a algunas de las seis vertientes de apoyo, sin embargo, todavía falta mucho por hacerse, no solamente de forma directa con el artífice y sus elaboraciones, sino también resulta necesario sensibilizar y emprender acciones que impliquen a la sociedad en general, pues vivimos en una sociedad aristotélica en la que podría valorarse y reconocer más el trabajo artesanal (Del Carpio, 2012). Resulta relevante, por ejemplo, emprender acciones respecto a aspectos educativos de las acciones de defensa y apoyo a los artesanos y a las artesanas; es esta una dimensión con mucho rezago.

Existe todavía una desvinculación entre el sistema educativo nacional y el sector artesanal que se expresa, por ejemplo, en el hecho de que no exista un programa formal de formación de docentes para que desarrollen competencias que les permita educar a los niños y adolescentes en la apreciación estética de la artesanía y en el reconocimiento de su valor cultural como elemento de fortalecimiento de la identidad (Turok, 2015). Otro aspecto relevante de la desvinculación es el hecho de que no existe un programa nacional de acreditación y certificación de saberes y oficios artesanales. Como plantea esta autora, importante es la acreditación y titulación de los artesanos que les permita sentirse orgullosos de su oficio y obtener el reconocimiento que merecen, es decir, es vital reflexionar sobre la acreditación y certificación con validez oficial de los saberes de los artesanos.

Necesario también es emprender estrategias que aborden los diferentes contextos sociales en los que circulan las artesanías y re-pensar 
las nuevas geografías del consumo artesanal. Estas transformaciones en el ámbito artesanal invitan también a pensar en que estas elaboraciones pareciesen cada vez más ligadas a la llamada "civilización urbana" y creyese, en muchas ocasiones, obedecer a su lógica, es decir, que se "acomodan" a sus demandas, gustos, modas y tendencias, más que a los ámbitos rurales en que fueron y son producidas. Área de oportunidad también es analizar la reinserción y redefinición de las comunidades en la modernidad. Estudiar las nuevas prácticas asociativas del sector artesanal resulta importante y los programas que pueden, aparte de Fonart, impulsar y apoyar al artesano y a sus productos, en el área de salud, adquisición, capacitación, comercialización (psicología del color, marketing, espacios de difusión como ferias, exposiciones, espacios online y venta a través de esta vía) y otros rubros son de vital importancia.

Sin duda, valioso es el objeto (la artesanía), pero más importante es quien la produce: el artesano, la artesana. En ellos debemos centrar nuestros esfuerzos, en sus condiciones de trabajo, ingresos y en el cuidado de su salud. Pues, como señala una artesana "(las artesanías), vivirán mientras haya quienes la realicen". Por ello, y por múltiples motivos más, debemos seguir interesados en los dueños y en las dueñas de esas manos que permiten que siga viva esta tradición transformadora.

\section{Conclusiones}

La reflexión sobre los informes recabados nos permite señalar varios aspectos. Uno de ellos es que en México se elaboran productos provenientes de una gran variedad de ramas artesanales cuyos productores tienen orígenes diversos. Es realizada por población mestiza e indígena de diferentes latitudes de México. Las ramas artesanales con mayor cantidad de artesanos empadronados en este país, por lo menos para el periodo que aquí se analiza, son los textiles, la alfarería y las fibras vegetales. En estas tres ramas artesanales las mujeres son quienes llevan la batuta en cuanto a cantidad de artífices registrados se refiere. Esta afirmación sigue vigente, pues se ha podido constatar, con información reciente de Fonart, que en los últimos años ha incrementado la población que esta instancia ha atendido, la cual, con relación a mujeres y 
hombres ha presentado un comportamiento promedio de atención que señala que del $100 \%$ de los beneficiarios, el $70 \%$ son mujeres y el $30 \%$ son hombres. Sobresale la participación, entonces, de las mujeres en el mundo artesanal.

Dígase también que quienes se dedican a la producción de artesanías enfrentan una serie de problemas. Esto lo indica no solo la revisión de la literatura aquí analizada, sino también el trabajo de campo de diversos estudios que hemos realizado en los cuales se ha constatado que los principales problemas del gremio tienen que ver con aspectos tales como la precariedad económica de los productores, la comercialización de los productos, la intermediación, los bajos precios, la competencia con productos industriales, el impacto del oficio en su salud y otras dificultades relacionadas con la necesidad de mayor organización, comunicación y acuerdo entre los integrantes del gremio.

En este panorama, los integrantes del gremio desarrollan una serie de estrategias para hacer circular sus productos y ampliar el público que consume sus elaboraciones que, en el caso de artesanos indígenas, hemos encontrado que mujeres jóvenes, por ejemplo -que no usan cotidianamente ropa tradicional de la comunidad- al vender sus productos lucen estos vestidos para "atraer" al turismo, pues "al cliente lo que pida". Observamos, en este sentido, un uso estratégico de la identidad (Gergen, 1991). Dentro de las áreas en las que consideran requieren capacitación, sobresalen las relacionadas con compradores, concursos, programas y convocatorias de apoyo.

Una estrategia desarrollada por los integrantes del gremio ha sido, sin duda, la apuesta a la innovación a través de la combinación de nuevos colores, formas, texturas y la fusión con nuevos materiales para hacer más "vistosa" y atractiva la producción artesanal. Requieren también información sobre protección de los derechos de autor colectivo ante el uso indiscriminado de los motivos y diseños artesanales que realizan y que pueden ser utilizados por empresas de ropa, accesorios y de otros productos (Turok, 2015).

Otra de las sugerencias a subrayar es la necesidad de vincular el sistema educativo nacional para, desde la educación básica, fomentar el gusto y la valoración de las artesanías y de elementos culturales de 
las comunidades originarias. Es necesario también estudiar las nuevas prácticas asociativas y generar políticas públicas para la innovación de estos oficios de antigua raigambre $y$, especialmente, para construir un panorama más alentador que implique un desarrollo integral para los artesanos y sus productos.

Lo dicho hasta ahora nos lleva a subrayar la necesidad de realizar investigación multidisciplinaria donde se exploren las dimensiones económica, cultural, ambiental, social y de salud de quienes realizan artesanías. Esto desde abordajes que también permitan ir construyendo conocimientos respecto a estrategias que debe desarrollar el gremio para emprender o enfrentar la competencia en el ámbito global y los retos que asumen quienes se dedican a construir la historia económica, social y cultural de este país desde el ámbito del trabajo y de los oficios artesanales.

\section{Referencias}

Angelotti, G. (2004). Artesanía prohibida: de cómo lo tradicional se convierte en clandestino. México, D.F.: Instituto Nacional de Antropología e Historia.
Arizpe, L. (1986). Las mujeres campesinas y la crisis agraria en América Latina. Revista Nueva Antropología, 8(30), pp. 57-65.

Bartra, E. (1998). Neozapatismo, arte popular y género. Recuperado de: http://lasa.international.pitt.edu/LASA98/Bartra.pdf

Boisier, S. (1999). El desarrollo territorial a partir de la construcción de capital sinergético. Estudos Urbanos e Regionais, (2), pp. 39-53.

Cardini, L. (2007). Reflexiones que convergen: aproximaciones a la producción artesanal indígena en la ciudad de Rosario. En M. Rotman, J. C. Radovich y A. Balazote (Eds.), Pueblos originarios y problemática artesanal: procesos productivos $y$ de comercialización en agrupaciones mapuches, guarani/chané, wichis/tobas $y$ mocovíes (pp. 251-270). Córdoba, Argentina: Universidad Nacional de Córdoba/CONICET.

Centro de Comercio Internacional UNCTAD/OMC (CCI) y Organización Mundial de la Propiedad Intelectual (OMPI) (2003). Marketing de la artesanía y las artes visuales: Función de la propiedad intelectual. Guía práctica. Ginebra: CCI/OMPI. 
Clements, H. (1988). Mujeres, trabajo y cambio social: el caso de dos comunidades oaxaqueñas. Las mujeres en el campo. Memoria de la primera reunión nacional sobre mujeres campesinas en México. Oaxaca: Universidad Autónoma Benito Juárez de Oaxaca.

Del Carpio, P. (2012). Entre el textil y el ámbar: Las funciones psicosociales del trabajo artesanal en artesanos tsotsiles de La Ilusión, Chiapas, México. Athenea Digital, 12(2), pp. 185-198. y Freitag, V. (2013). Motivos para seguir haciendo artesanías en México: convergencias y diferencias del contexto artesanal de Chiapas y Jalisco. Ra Ximhai. Revista Cientifica de Sociedad, Cultura y Desarrollo Sustentable, 9(1), pp. 79-98.

Fábregas, A., y Santos, C. (2000). Una mirada antropológica a las artesanías de Chiapas. En V. Novelo (Coord.), Artífices y artesanias de Chiapas (pp. 24-79). México: CONACULTA/ CONECULTA

Fonart (2014). Manual de diferenciación entre artesanías y manualidades. Recuperado de: $\underline{w w w . f o n a r t . o r g . m x}$ (2016). Vertientes del Fondo Nacional para el Fomento de las
Artesanías. Recuperado de: https:// www.fonart.gob.mx/web/index.php/ programas-sociales (2016). Porcentaje de artesanos beneficiarios por el programa Fonart, distribuido por sexo. Recuperado de: https://www.fonart.gob. mx/web/images/pdf/Transparencia/ porcentaje artesanos beneficiarios fonart.pdf

García Canclini, N. (1982/1986). Las culturas populares en el capitalismo. México: Nueva imagen.

(1989). Culturas híbridas. Estrategias para entrar y salir de la modernidad. México: Grijalbo.

Good Eshelman, C. (1988). Haciendo la lucha. Arte y comercio nahuas de Guerrero. México: Fondo de Cultura Económica.

Gergen, K. (1991). El yo saturado. Barcelona: Paidós.

Hammersley, M., y Atkinson, P. (1994). Etnografía: Métodos de Investigación. Barcelona: Paidós.

Köhler, H.D., y Artiles, A. M. (2007). Manual de la Sociología del Trabajo $y$ de las Relaciones Laborales. Delta Publicaciones. 
León, O. (2009). América Latina en movimiento. Quito, Ecuador: Agencia Latinoamericana de Información.

Littlefield, A. (1976). La industria de las hamacas en Yucatán. México: INI/ SEP.

Mandujano, C.; Del Carpio, P. y Martínez, F. (2016). De Acámbaro y sus acambaritas, un oficio artesanal en transformación. Tecsistecatl. Economía y Sociedad de México, 8(20), pp. 1-21.

Martínez, P. (1982). Permanencia, cambio y extinción de la artesanía en México. México: FONART/FONAPAS.

Mateus, J. R. y Brasset, D. W. (2002). La globalización: sus efectos y bondades. Economía y Desarrollo, 1(1), pp. 65-77.

Morey, E. (2007). Artesanías en Misión Chaqueña, continuidades y transformaciones en las formas de disciplinamiento laboral en contextos de formación social de fronteras. En M. Rotman, J. C. Radovich y A. Balazote (Eds.), Pueblos originarios y problemática artesanal: procesos productivos y de comercialización en agrupaciones mapuches, guaraní/chané, wichís/tobas y mocovíes (pp. 217-249).
Córdoba, Argentina: Universidad Nacional de Córdoba/CONICET.

Novelo, V. (1976). Artesanías y Capitalismo en México. México: SEP/ INAH.

(1993). Las Artesanías en México. Tuxtla Gutiérrez: Instituto Chiapaneco de Cultura, Chiapas.

(1997). Las artesanías mexicanas. En E. Florescano (Coord.), El patrimonio nacional de México, II (pp. 111-129). México: FCE. (2002). Ser indio, artista y artesano en México. Espiral, 9(25), 165-178.

(2004). La fuerza de trabajo artesanal en la industria mexicana. Exposición presentada en el Segundo Congreso Nacional de Historia Económica. México, D.F.

Pedraza, L. A. (2010). Lacas mexicanas, tradiciones paralelas realidades diversas en Olinalá, Guerrero y Uruapan, Michoacán. Memorias del XXXII Coloquio de antropología e Historia Regionales (Recurso electrónico). Zamora: COLMICH.

Pérez, H. (2015). El sentido de las artesanías en el concierto de la cultura. En Salvador Pérez (Coord.), 
Artesanías y saberes tradicionales. 1 (pp. 47-52). Zamora: Colegio de Michoacán.

Ramos, T. (2010). Artesanas tseltales. Tuxtla Gutiérrez: UNICACH.

Stephen, L. (1990). La cultura como recurso. América Indígena, 4.

Sedesol (2015). Diagnóstico del programa del Fondo Nacional para el Fomento de las Artesanías. Recuperado de: http://www.gob.mx/cms/uploads/ attachment/file/32059/Diagnostico FONART 1 -1-40.pdf

(2016). Diagnóstico de la capacidad de los artesanos en pobreza para generar ingresos sostenibles. Recuperado de: http://www.gob.mx/ cms/uploads/attachment/file/32043/ Diagnostico FONART 3 .pdf

Turok, M. (1988). Cómo acercarse a las artesanías. México: Plaza y Valdés. (2015). El artesanado tradicional. Disyuntivas para su supervivencia. En Salvador Pérez (Editor), Artesanías y saberes tradicionales. 1 (pp. 77-97). Zamora: El Colegio de Michoacán.

UNESCO (1997/2015). Simposio UNESCO/CCI "La Artesanía y el mercado internacional: comercio y codificación aduanera", Manila, 6-8 de octubre de 1997. Recuperado de: http://www.unesco.org/new/es/culture/themes/creativity/creative-industries/crafts-and-design/

Valverde, S. (2007). Actividad artesanal indígena: procesos de producción y comercialización en la comunidad Mapuche Chiuquilihuín. En M. Rotman, J. C. Radovich y A. Balazote (Eds.), Pueblos originarios y problemática artesanal: procesos productivos $y$ de comercialización en agrupaciones mapuches, guarani/chané, wichís/tobas y mocovies (pp. 95-126).Córdoba, Argentina: Universidad Nacional de Córdoba/CONICET.

Zapata, E. y Suárez, B. (2007). Las artesanas, sus quehaceres en la organización y en el trabajo. Ra Ximhai. Revista de Sociedad, Cultura y Desarrollo Sustentable, 3, pp. 591-620. 